\title{
СИМВоЛИЗМ
}

\author{
Р.Н. Пархоменко
}

\section{ВЕРБАЛЬНАЯ РЕАЛЬНОСТЬ У Э. КАССИРЕРА}

\begin{abstract}
Аннотация. Свою собственную концепцию философии языка Кассирер развивает в четырех главах первого тома "Философии символических форм", где последовательно рассматривается функционирование языка на стадии чувственного и эмоционального выражения - здесь он дает понимание языка на первоначальной стадии развития человеческого общества как выражения движения. Кассирер ссылается на психологические и эстетические исследования, проведенные еще в XIX веке Дж. Энгелем, а также на работу Вундта «Язык». В основе этой концепции лежит идея, что первоначально движение и чувство движения образуют круг понятий, определяющих содержание сознания, а сознание представляет собой лишь сумму “связей» и состояний. Кроме этого, Кассирер обращается и к идеям Германа Когена, который также рассматривал движение и чувство движения как элемент и как основной фактор в построении человеческого сознания.

Методологией исследования выступило изучение тестов Э. Кассирера и критической литературы о нем, которым автор статьи занимается уже на протяжении более десяти лет.

В статье показано, что Кассирер реконструирует эволюцию понятия «язык» от мимической и аналоговой стадии, через стадию символического выражения - к языку понятийного и концептуального мышления вплоть до наиболее абстрактного языка современной науки. Поскольку Кассирер "разбивает» единый универсум человеческой культуры на ряд автономных областей и язык представляет одну из таких областей, то для того, чтобы прояснить место и значение языка среди прочих феноменов человеческой культуры, он постоянно соотносит язык с миром, религией, искусством и наукой.
\end{abstract}

Ключевые слова: Эрнст Кассирер, язык, феноменология языка, философия языка, человек, культура, символ, сознание, знак, символическая форма.

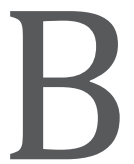

предисловии к первому тому «Философии символических форм» Кассирер пишет, что этот том в своих общих чертах связан с его первой систематической книгой «Понятие субстанции и понятие функции». Однако выработанный в то время метод исследования структуры математического и естественнонаучного знания необходимо было значительно доработать для того, чтобы стало возможным применять этот метод в области наук о духе. «Вместо исследования только всеобщих предпосылок научного познания мира, необходимо перейти к тому, чтобы определить различные основные формы «понимания» мира, отграничить их друг от друга и каждую описать настолько четко, насколько это возможно в ее собственной тенденции и ее собственной духовной форме» ${ }^{1}$. При этом Кассирер подчеркивает, что учение о естественнонаучном образовании понятий и суждений (разработанное им в «Понятии

1 Cassirer E. Philosophie der symbolischen Formen. Bd. 1. S. 5. субстанции и понятии функции»), которое определяется в своих основных конститутивных чертах через «объект» природы, через «предмет» познания в его познавательной функции, может быть также по аналогии быть использован в области чистой субъективности.

Необходимо показать, считает философ, как духовные формообразования выполняют свои собственные задачи в построении духовного мира и на какие особенные законы они опираются. Исследуя эту проблему, Кассирер развивает план всеобщей теории духовных форм выражения. Как отмечает Х. Петцольд ${ }^{2}$ в первом томе «Философии символических форм» Кассирер во многом опирается на теорию языка В. Гумбольдта. Вильгельм фон Гумбольдт разработал новую парадигму языкового мышления, оригинальность которой в наибольшей степени проявилась при решении вопроса о про-

2 Paetzold H. Ernst Cassirer. Zur Einführung. Hamburg, 1993. S. $69-70$. 


\section{Филология: научные исследования 2(14) 2014}

исхождении языка. По мнению Гумбольдта, язык следует рассматривать скорее как деятельность, чем как результат действия. Это не готовая вещь, а непрерывный процесс - вечно повторяющаяся работа человеческого духа по использованию артикулированных звуков для выражения мысли.

И если во «Введении и постановке проблемы» Кассирер создает общую теорию символа, то уже собственно первый том «Язык» носит подзаголовок «К феноменологии языковых форм» и состоит из пяти глав. Сильной стороной философствования Кассирера является то, что он всегда свою собственную концепцию дает на фоне возникновения и развития определенной идеи в истории философии. В первой главе - «Проблема языка в истории философии» прослеживается развитие и трансформация проблем философии языка в различных философских учениях: в истории философского идеализма (Платон, Декарт, Лейбниц), в системе эмпиризма (Бэкон, Гоббс, Локк, Беркли), в философии французского Просвещения (Кондильяк, Дидро). Кассирер специально рассматривает и концепцию языка как выражения аффектов и связанную с этим проблему «первоначала» языка (Джамбатиста Вико, Гаманн, Гердер), концепции В. Гумбольдта и А. Шляйхера, дальнейший переход к «естественнонаучному» пониманию языка. Заканчивается эта глава рассмотрением вопросов обоснования современного языкознания. Свою собственную концепцию философии языка Кассирер развивает в последующих четырех главах первого тома «Философии символических форм», где последовательно рассматривается функционирование языка на стадии чувственного и эмоционального выражения (глава 2) здесь философ дает понимание языка на первоначальной стадии развития человеческого общества как выражения движения. Кассирер ссылается на психологические и эстетические исследования, проведенные еще в XIX веке Дж. Энгелем в его «Идеях к мимике» (Берлин, 1801), а также на работу Вундта «Язык». В основе этой концепции лежит идея, что первоначально движение и чувство движения образуют круг понятий, определяющих содержание сознания, а сознание представляет собой лишь сумму «связей» и состояний. Кассирер отмечает, что Герман Коген также рассматривал движение и чувство движения как элемент и как основной фактор в построении сознания (Г. Коген. «Эстетика чистого чувства») ${ }^{3}$.

3 Cassirer E. Philosophie der symbolischen Formen. Bd. 1. S. 126.
Далее Кассирер рассматривает переход от языка мимики и жестов к появлению слов и выражений. Он выделяет три стадии, приведшие к появлению языка как системы символов: мимическую, аналоговую и собственно символическую. На мимической стадии существуют лишь элементы различия громкости и длительности звука, язык носит физиогномический характер. При переходе от мимической к аналоговой стадии с помощью громкости звука выражается уже отношение к предмету, что постепенно приводит к возможности выражения этого предмета и, наконец, к интеллектуальному языку, к превращению его в чисто символическую систему.

И если во второй главе Кассирер рассматривает язык на стадии чувственного выражения, в третьей главе - стадию наглядного выражения, соответствующую интуитивному и обыденному сознанию, то в четвертой главе язык исследуется как выражение понятийного мышления и прослеживаются языковые формы создания понятий и классов. В заключительной, пятой главе первого тома «Философии символических форм», язык представлен на стадии выражения «форм чистых отношений», то есть в науке - так Кассирер прослеживает логику развития абстрактного мышления у человека, где важнейшую роль, по его мнению, играет понятие символа.

Необходимо подчеркнуть, что Кассирер не ограничивается рассмотрением языка в первом томе «Философии символических форм». Язык как система символов и как одна из символических форм, образующих универсум человеческой культуры, постоянно используется им для анализа и характеристики других символических форм: мифа, религии, искусства и науки. Именно в сопоставлении последних с языком, немецкий неокантианец пытается найти сходство и различие между языком и остальными частями символического мира культуры, что дает возможность показать, с одной стороны, автономность и оригинальность каждой символической формы, а с другой - взаимосвязь и целостность символического универсума культуры.

Поэтому языковая проблематика присутствует не только во втором томе - «Мифическое мышление» и в третьем томе «Феноменология познания» главного произведения Кассирера, но и в «Опыте о человеке», также содержащем специальную главу «Язык». Поскольку главной проблемой нашей диссертации является проблема человека как субъекта культуры в философии Э. Кассирера, то в дальнейшем представляется необходимым рассмотреть 


\section{Символизм}

философию языка Кассирера через призму его антропологического учения.

Кассирер показывает, что язык и миф родственны друг другу. На ранних стадиях развития человеческой культуры их отношения столь тесны и взаимосвязь столь очевидна, что их невозможно отделить друг от друга. Язык и миф основываются на подлинно всеобщем и изначальном человеческом опыте, но опыте не физической, а скорее социальной природы. Задолго до того, как ребёнок научился говорить, были открыты другие, гораздо более простые средства общения человека с другими людьми. По Кассиреру, крики беспокойства, боли или голода, распространенные повсюду в органическом мире, у человека начинают приобретать новую форму. Это уже не просто инстинктивные реакции - они используются с осознанным намерением. Ребёнок, требующий пищи с помощью нечленораздельных звуков, скоро узнает, что эти требования приводят к желаемому результату. Здесь особенно важно то, что первобытный человек начинает распространять этот первый элементарный социальный опыт на все мироздание.

Кассирер отмечает, что природа и общество для первобытного человека образуют нерасторжимое целое - именно исходя из этого, можно понять использование и специфическую функцию магического слова, поскольку вера в магию, как считает философ, основана на глубоком убеждении во всеединстве жизни.

Эти идеи Кассирер подробно разрабатывает во втором томе «Мифическое мышление». Здесь же для нашей темы важно отметить то, что, первобытный человек, по Кассиреру, чувствует себя окруженным всякого рода видимыми и невидимыми опасностями. У него нет надежды преодолеть эти опасности одними лишь физическими средствами. Мир для первобытного человека не мертв и безмолвен - он может слышать и понимать человека. Значит, если правильно обратиться к силам природы, они не смогут отказать ему в помощи, именно отсюда и проистекает вера первобытного человека в магию слова.

Однако со временем человек начинает осознавать тщетность своей доверчивости, природа не подчиняется магическим заклинаниям и не выполняет требований человека. Это явилось свидетельством новой проблемы, коренным образом изменившей мироощущение и миропонимание человека - отныне человек начинает ощущать глубочайшее одиночество, чувствует себя в полной заброшенности. Как считает Кассирер, человек едва ли смог бы преодолеть такое состояние, если бы не развивал новые духовные силы, которые, с одной стороны, преградили путь магии и вытеснили ее в область, которую условно можно назвать «маргиналиями культуры», а с другой - открыли новые, гораздо более перспективные пути развития человеческого духа. И хотя рухнули все надежды подчинить природу магическому слову, но зато перед человеком предстало в совершенно ином свете соотношение между языком и реальностью. Кассирер подчеркивает, что магическая функция слова ушла в тень, сменившись семантической функцией.

«Слово лишилось таинственной власти, оно не имеет более непосредственного физического или сверхъестественного воздействия, оно не может изменить природу вещей и подчинить их воле богов и демонов. Но это не означает потерю им всякого значения и власти. Это не просто flatus vocis, дуновение ветерка. Самое главное в слове - не физические, а логические его свойства. Слово можно считать физически бессильным, однако в логическом смысле оно занимает отныне более высокое, быть может, даже самое высокое место. Логос становится принципом универсума и первым принципом человеческого познания» ${ }^{4}$. Из этого следует, что в своей трактовке языка Кассирер полностью следует установкам Марбургской школы, подчеркивая именно логическую основу языкового мышления. Философ пытается обосновать этот свой тезис, обращаясь к истории философии и культуры.

Хронологически такое понимание языка, говорит он, возникает еще в ранней греческой философии. Даже Гераклит, интересы которого сосредоточивались целиком на мире явлений, все же не довольствовался лишь констатацией факта изменений, он ищет их принцип. Согласно Гераклиту, принцип этот не следует искать в материальных вещах: ключ к верному истолкованию космического порядка - не в материальном, а в человеческом мире, в котором главное место занимает речевая способность. Следовательно, невозможно понять «значение» универсума, не уяснив, что значит язык, Если нам не удастся найти этот путь к миру - путь через язык, а не через явления природы, мы не достигнем истинной философии. Ведь даже в гераклитовом мышлении, подчеркивает Кассирер, слово, Логос, не только антропологический феномен, он не ограни-

\footnotetext{
4 Кассирер Э. Опыт о человеке. Введение в философию человеческой культуры // Кассирер Э. Избранное. Опыт о человеке. М., 1998. С. 570-571.
} 


\section{Филология: научные исследования 2(14) 2014}

чен ближайшими пределами нашего человеческого мира, ведь логос является обладателем универсальной космической истины. Но теперь слово, в отличие от первобытного мышления уже не выступает в качестве магической силы - оно понимается в его семантической и символической функции.

Зафиксировав эту принципиально важную идею о переходе в раннегреческой философии от изучения природы к исследованию языка, Кассирер обращается к другой фундаментальной проблеме, которую он называет проблема «значения значения». Слово не могло бы «обозначать» вещь, если бы между тем и другим не было бы по крайней мере частичного тождества. Связь между символом и тем, что он обозначает, должна быть естественной, а не только условной, конвенциальной. Без такой естественной связи слово, считает Кассирер, не могло бы выполнять свою задачу: оно стало бы непонятным. Для пояснения этой мысли Кассирер приводит три различных концепции функций и значения языка: мифологическую, метафизическую и прагматическую.

Мифологическая концепция восходит к философии Сократа и Платона - это учение о звукоподражании в процессе возникновения языка. В платоновском «Кратиле» Сократ делает вид, будто бы принимает этот тезис, с тем, чтобы разбить, его показать его полную абсурдность. Таким образом, преодоление разрыва между названиями и вещами не происходит.

Метафизическое учение о значении Кассирер связывает, прежде всего, с именем Гераклита. У Гераклита логос был универсальным метафизическим принципом, он обладал общей истинностью и объективной значимостью. Для софистов же, представляющих третью, прагматическую трактовку значений в языке, слово уже не является божественным логосом, в котором содержится начало всех вещей, космического и морального порядка. Антропология, а не метафизика играет у софистов ведущую роль в теории языка. Согласно Протагору, «человек есть мера всех вещей» и, таким образом, человек становится центром вселенной. Софисты были первыми, кто дал системное истолкование лингвистических и грамматических проблем. Правда, у них центр тяжести рассмотрения языка находится в области риторики, а не грамматики или этимологии. Теория языка, по их мнению, должна учить человека говорить и действовать в окружающей его социальной и политической жизни и добиваться своих целей. Таким образом, они разработали прагматическую концепцию языка.
Но, как отмечает Кассирер, все эти три подхода к изучению языка - мифологический, метафизический и прагматический - не выделяют одну из наиболее значимых черт языка. Хотя самые элементарные человеческие высказывания не соотносимы напрямую с физическими вещами, но они вместе с тем и не являются лишь произвольными знаками. Как метко подмечает Кассирер, альтернатива «по природе» или «по соглашению» к ним просто не применима. Человеческие высказывания «естественны», а не «искусственны», но они не имеют отношения к природе внешних объектов. Не зависят они и от соглашения, равно как и от привычек и обычаев, они укоренены гораздо глубже. Здесь Кассирер придерживается теории происхождения языка из междометий, согласно которой язык непроизвольно выражает человеческие чувства, возгласы и восклицания.

Демокрит был первым, кто утверждал, что человеческая речь произошла от некоторых звуков чисто эмоционального характера. Через Эпикура и Лукреция эти идеи появляются вновь в XVIII веке у Вико и Руссо. Преимущество «теории междометий» в том, что она обнаруживает некоторые проверяемые факты и больше нет нужды обращаться к чистой спекуляции. Но в ней есть и другая крайность, на которую указывает Кассирер - человеческая речь может быть сведена к основным инстинктам, которыми природа наделила все живые существа, таким образом, есть опасность превращения семантики из специальной науки о языке в раздел биологии или физиологии.

Авторы биологических теорий происхождения языка (Кассирер называет здесь имена Чарльза Дарвина и Августа Шлейхера) исходят из утверждения, что от восклицания лежит прямой путь к речи. Но, по мнению немецкого неокантианца, это лишь постановка вопроса, а не его решение, ведь в объяснении нуждается не только факт, но сама структура человеческой речи. Анализ этой структуры и выявляет радикальное различие между эмоциональным и пропозициональным языками, поскольку они принадлежат к разным уровням рассмотрения проблемы. В чем здесь суть дела?

Кассирер поясняет: так называемый «животный язык» всегда остается целиком субъективным он выражает различные чувства, но не способен обозначать или описывать объекты. С другой стороны, не существует исторических свидетельств того, что язык человека даже на самых ранних стадиях развития когда-либо сводился к чисто эмо- 


\section{Символизм}

циональному языку или языку жестов. Кассирер ссылается на концепцию языка Отто Есперсена ${ }^{5}$, согласно которой человеческие высказывания, бывшие дотоле лишь эмоциональными криками, превращаются в членораздельную речь только после того, как они начинают использоваться как имена, что, в свою очередь, ведет к появлению такого феномена как символ. Это приводит к тому, что бывшая ранее бессвязной масса звуков, лишенных определенного значения, вдруг становится орудием мысли. Звуковые выражения, которые ранее были лишь выкриками, невольной разрядкой сильных эмоций, теперь направлены на решение совершенно иной задачи: они используются в качестве символов, передающих определенное значение. Язык, согласно Есперсену, появляется тогда, когда установка на сообщение начинает преобладать над установкой на выражение эмоций. Кассирера, однако, не удовлетворяет то, как лишь одна теория выкриков может объяснить этот решающий шаг, поскольку разрыв между возгласами и именами все еще остается значительным.

Прежде чем перейти к собственной трактовке языка, Кассирер детально анализирует концепции В. Гумбольдта, С. Соссюра и Н. Трубецкого, которые помогли ему разработать свою теорию языка как одной из символических форм полицентричного универсума человеческой культуры. По мнению философа, при анализе человеческой культуры факты надлежит принимать в их конкретной форме, во всем их разнообразии и различиях. Философия языка сталкивается здесь с той же самой дилеммой, что и при изучении любой символической формы. Высшая и по существу единственная задача всех этих форм - объединение людей. Но ни одна из них не может осуществить такое единение без разделения, разъединения людей. Здесь человечество опять сталкивается с великой дилеммой: то, что должно было бы способствовать гармонии культуры, становится источником глубочайших разладов и расколов. Так происходит в религии, но те же процессы можно наблюдать в языке: без речи не может быть сообщества людей, но нет, однако, ничего более мешающего такому сообществу, чем различие языков и даже многозначность и полисемия каждого конкретного языка. Кассирер пытается найти решение данной проблемы с помощью понятия функции. Если и существует подлинное единство языка, то

\footnotetext{
5 Впервые эта теория была выдвинута Есперсеном в книге: Espersen O. Progress in Language. L., 1894.
}

оно «не может быть чем-то субстанциальным - это скорее функциональное единство» ${ }^{6}$.

Здесь не идет речь о материальном или формальном тождестве. Два различных языка, несмотря на всю их несхожесть, могут выполнять одни и те же функции в жизни общества. Главное при этом не разнообразие средств, а их уместность, соответствие единой цели. Коль скоро задача человеческой речи состоит в том, чтобы копировать или имитировать данный порядок вещей, то мы не можем прийти к выводу, что какой-либо язык может быть лучше, чем другие языки, может лучше и адекватнее отображать реальность. Если же, однако, предоставить речи продуктивную и конструктивную, а не только репродуктивную функцию, дело предстает в ином свете. В этом случае вовсе не «работа» языка, а его «энергия» будет иметь первостепенное значение. Кассирер, ссылаясь на мнение психологов, подчеркивает, что без проникновения в подлинную природу человеческой речи наше знание о развитии человеческого разума останется поверхностным и ущербным.

И здесь Кассирер придерживается точки зрения, что интеллектуальное развитие человека начинается только тогда, когда человек начинает усваивать ключевой символизм. У ребёнка интеллектуальное развитие идет в направлении от более субъективного состояния к объективному, от всецело эмоциональной установки к теоретической. Общая черта нормального развития ребёнка заключается в том, что «в начале двадцать третьего месяца у ребёнка развивается мания называния всех вещей вокруг: он словно стремится назвать их имена другим людям или привлечь их внимание к интересующим его вещам. Он смотрит на тот или иной предмет, указывает на него рукой, называет его имя, а потом смотрит на взрослого» ${ }^{7}$

Кассирер также придает первостепенное значение функции именования в умственном развитии ребёнка. Если бы ребёнок, учась говорить, просто усваивал некоторый словарь, если бы в его уме и памяти запечатлевались огромные массы искусственных и произвольных звуков, это был бы всего лишь механический процесс. Но, что важно отметить, в процессе развития любого рёбенка психологи сталкиваются с таким феноменом, который можно условно назвать «голод по именам». Это как

\footnotetext{
6 Cassirer E. Philosophie der symbolischen Formen. Bd. 1. S. 294.

Major David R. First steps in Mental Growst. N.Y.: Macmillan,
} 1906. P. 321 


\section{Филология: научные исследования 2(14) 2014}

раз и доказывает обратное: «именование» вещей не является для ребёнка мучительным и скучным процессом, требующим огромных усилий. Изучая имена вещей, ребёнок не просто дополняет список искусственных знаков к предшествующему знанию готовых эмпирических объектов: скорее, он учится формировать понятия об этих объектах, вступать в отношения с объективным миром.

Как отмечает Кассирер, благодаря процессу «именования» вещей «ребёнок обретает твердую почву под ногами. Его туманные, неотчетливые, расплывчатые ощущения и неясные чувствования начинают складываться в новую форму. Они, можно сказать, кристаллизуются вокруг имени как фиксированного центра, фокуса мысли. Без помощи имени каждый новый шаг в процессе объективации подвержен риску потеряться в следующее же мгновение. Первые имена, сознательно используемые ребёнком, можно сравнить с тростью слепого, с помощью которой он нащупывает путь. А язык, взятый как целое, становится воротами, открывающими путь в новый мир. Всякий следующий шаг здесь открывает новую перспективу, расширяет и обогащает наш конкретный опыт. Рвение и страстное стремление говорить порождено не одним лишь желанием узнавать и использовать имена, но желанием обнаружить и подчинить себе объективный мир ${ }^{8}$.

Необходимо заметить, что Кассирер, для того, чтобы убедительно обосновать свою концепцию языка, не только обращается к конкретным исследованиям в области психологии, рассматривает случаи аномалий в развитии речи, но публикует также сам специальные отдельные работы, где он, к примеру, подробно рассматривает проблему объективации в процессе именования ${ }^{9}$.

Применительно к проблеме именования вещей, Кассирер рассматривает также вопрос о сравнении различных языков. Это сравнение показывает, что невозможно найти точные синонимы в разных языках, соотносительные термины двух языков редко приложимы к одним и тем же предметам или действиям. Кассирер объясняет это тем, что данные термины покрывают различные поля, которые, взаимопроникая, создают многоцветную картину и различные перспективы нашего опыта.

Для пояснения этой мысли философ обращается к такому явлению, как классификация в языке.

\footnotetext{
8 Кассирер Э. Избранное. Опыт о человеке. М., 1998. С. 595.

9 См.: Cassirer E. Le language et la construction du monde des
} objets // Journal de Psychologie. XXX e Annee, 1933. P. 18-44.
Классификация, по мнению Кассирера, фундаментальная черта человеческой речи. От процесса классификации зависит сам акт деноминации. Дать имя предмету или действию - это значит отнести его к некоторому классу понятий. Если бы это отнесение предписывалось самой природой вещей, оно было бы единым и единообразным. Однако имена, которые используются в человеческой речи, невозможно истолковать одним неизменным способом. Они не относятся к субстанциальным вещам, независимым, самостоятельно существующим сущностям. Скорее, они определяются человеческими интересами и целями.

И хотя эти интересы неустойчивы и непостоянны, все же классификации в человеческой речи не случайны. Как подчеркивает философ, все классификации основаны на некоторых постоянных и повторяющихся элементах нашего чувственного опыта. Без таких повторений у наших лингвистических понятий не было бы никакой точки опоры, никакого фундамента.

Здесь возникает определенный комплекс проблем, поскольку сочетание и отбор перцептивных данных зависят от свободного выбора рамок референции. Конечно, пишет Кассирер, не существует жесткой и заранее раз и навсегда установленной схемы, согласно которой происходит расчленение и подрасчленение нашего опыта. Даже в родственных и близких по общей структуре языках мы не находим одинаковых имен. Кассирер ссылается на Гумбольдта, который подчеркивал, что в греческом и латинском языках термины, обозначающие луну, не выражают одинаковые замысел и понятие, хотя и относятся к одному и тому же объекту. Греческий термин (men) обозначает функцию луны «измерять» время; латинский термин (luna, luc-na) обозначает лунный свет или блеск. Очевидно, что здесь внимание направляется и сосредоточивается на двух совершенно различных чертах объекта. Однако сам акт концентрации и сосредоточения в обоих случаях один и тот же. Имя объекта не претендует на выражение природы объекта, оно не претендует на то, чтобы давать нам истину вещи.

По мнению Кассирера, функция имени всегда ограничивается тем, чтобы подчеркнуть отдельные аспекты вещи, и именно этим ограничением, обозначением пределов определяется ценность имени. «Функция имени вовсе не в том, чтобы исчерпывающе соотнести имя с конкретной ситуацией, а как раз в том, чтобы отобрать, выделить только один какой-то аспект. Выделение этого аспекта 


\section{Символизм}

- вовсе не негативный, а позитивный акт. Ибо в акте именования мы отбираем из множества рассеянных чувственных данных некоторые устойчивые центры восприятия».

Кассирер считает, что такие центры восприятия не совпадают с центрами логической или научной мысли, поскольку термины обыденной речи характеризуются определенными особенностями, отличающими их от научных понятий. Эти особенности проявляются в том, что в обыденной речи всегда имеется элемент некоторой неточности, расплывчатости, туманности. Кассирер считает, что это проистекает оттого, что все слова обыденной речи не проходят испытание логическим анализом. Однако, вопреки этому неизбежному и неустранимому недостатку, обыденные термины и названия являются важными вехами на пути к научным понятиям и концептам, в которых мы впервые получаем объективную или теоретическую точку зрения на мир.

Философ подчеркивает, что такая точка зрения не просто «дана»: она является результатом конструктивных интеллектуальных усилий, который, в свою очередь, не может быть достигнут без постоянного содействия языка. Конечно, эту цель нельзя достичь быстро и сразу - этот подъем к высшим уровням абстракции, к более общим и всеохватывающим именам и идеям - тяжелая и трудоемкая задача. И именно анализ языка снабжает нас богатым материалом для изучения мыслительных процессов, которые в конечном счете приводят к решению этой задачи. Кассирер считает, что человеческая речь эволюционирует от сравнительно конкретного ко все более абстрактному состоянию. Первые названия всегда конкретны: они относятся к пониманию отдельных фактов или действий. Все оттенки и нюансы нашего конкретного опыта описываются детально и обстоятельно, но они не включаются в общий род.

Кассирер приводит пример из работы ХаммерПургшталя ${ }^{10}$, где перечисляются все названия аравийского верблюда. Не менее пяти-шести тысяч терминов используются для этого описания, но ни один из них не дает общего биологического понятия. Все эти термины фиксируют конкретные детали, относящиеся к форме, величине, цвету, возрасту, походке животного. Эти подрасчленения весьма далеки от какой-либо научной или систематической классификации - они служат совсем иным целям. Кассирер

10 Hammer-Purgstall. Wiener Academie, Philosoph.-hystorisch. Klasse. Bde. YI-YII, f 1855. считает, что каждая классификация вызывается и направляется особыми потребностями, а эти потребности, конечно, варьируются сообразно с условиями человеческой социальной и культурной жизни.

В первобытных цивилизациях по необходимости преобладает интерес к конкретным и частным аспектам вещей. По Кассиреру, человеческая речь всегда соответствует тем или иным формам человеческой жизни и соизмерима с ними. Интерес к «универсалиям», к примеру, не только невозможен, но и не нужен индейскому племени. Его членам достаточно - и это гораздо более важно - различать некоторые видимые и осязаемые черты объектов. Таким образом, «восхождение к универсальным понятиям и категориям происходило... очень медленно в развитии человеческой речи, но каждый новый шаг в этом направлении вел к более глубокому охвату, к лучшей ориентации и организации мира наших восприятий» ${ }^{11}$.

Резюмируя все вышеизложенное, можно сказать, что язык, с точки зрения немецкого неокантианца, является определенной символической формой культуры, важнейшей составляющей частью всего континуума духовного творчества человека, поскольку именно с возникновением членораздельной речи начинается собственно интеллектуальное развитие человечества, приведшее к созданию культуры, общества и науки. Именно с помощью языка начинают вытесняться из сознания экспрессивные моменты, которые занимали главенствующее положение в мифе и религии. Языкэто первая форма расчленения действительности в соответствии с конструктивными проектами духа, первая форма отдаления от непосредственно данного. Погружаясь в чувственное, язык в то же время осуществляет освобождение от него, то есть феноменальный мир оформляется в языке в соответствии с определениями сознания ${ }^{12}$.

Однако, несмотря на то, что язык является первой знаковой системой, в определенном смысле лежащей в основе всего здания науки, он все же несет в себе следы чувственной интуиции, что, по Кассиреру, является ограниченностью языка. В качестве проявления такой ограниченности он называет связь языковых понятий с пространственными интуициями, с действием и волей человека, а также несистематичность - в сравнении с научными -

\footnotetext{
11 Кассирер Э. Избранное. Опыт о человеке. М., 1998. С. 599.

12 См.: Cassirer E. Philosophie der symbolischen Formen.
} Bd. 1. S. 228 


\section{Филология: научные исследования 2(14) 2014}

языковых классификаций. Все эти несовершенства обыденного языка преодолеваются в науке. Языковая объективация феноменального мира создает мир интуиции (т.е. обыденного сознания), в то время как наука формирует мир идеальных значений, сферу чистых отношений. Подробно эту тему философ рассматривает в пятой главе первого тома «Философии символических форм», которая называется «Язык как выражение связи логических форм. Понятие отношения», которая является, с одной стороны, как бы отсылкой к произведению «Понятие субстанции и понятие функции», а с другой, «мостом» к третьему тому «Философии символических форм» «Феноменологии познания».

Важный момент в понимании философии языка Кассирера заключается в том, что наука, преодолевая ограниченность обыденного языка, все же не изменяет символического характера культуры, феноменом и составной частью которой наука является. Язык как система символов, лежащая в основе научного мышления, определяет роль и значение символа для научного знания. Роль символа в науке ничуть не меньше, чем в других областях гуманитарной культуры. Каждый шаг в формулировке проблем и понятий в науке сопряжен с развитием системы знаков.

Знак «служит не просто для того, чтобы сообщить завершенное и данное содержание мысли, а есть инструмент, посредством которого это содержание развивается и полностью определяет себя. Концептуальное определение содержания идет рука об руку с его закреплением в определенном характерном знаке» ${ }^{13}$. Например, лишь создание символических средств дифференциального исчисления дало универсальный метод, с помощью которого была уяснена единая сущность вопросов, исследовавшихся до Ньютона и Лейбница с различных точек зрения и в различных разделах математики ${ }^{14}$.

Различие между миром науки и миром интуиции состоит в том, что в рамках первой употребление символических средств является осознанным и целенаправленным, интуитивная же картина мира полностью определена языковыми противопоставлениями. Из потока образов язык впервые выделяет стабильные образования - вещи (отдельное), совершая тем самым расчленение реальности на вещи и свойства, субстанции и атрибуты, «я»

13 Cassirer E. Philosophie der symbolischen Formen. Bd. 1. Darmstadt, 1997. S. 86.

14 Ibid. S. 109-110. и «не-я», характерное для интуитивной картины мира. Кассирер уделяет большое внимание сравнительному анализу языка обыденной речи и языка теоретической науки в третьем томе «Философии символических форм», где также подчеркивается определяющая роль символа в построении научного знания.

Кассирер считает, что расчленение как языка, так и мира интуиции явилось продуктом так называемой репрезентативной функции сознания. Благодаря этой функции отдельные феномены потока образов сознания теряют свою независимость и расплывчатость и с помощью символической функции сознания приобретают отнесенность к некоторым вещам. Так с помощью репрезентации, в основе которой лежит способность создавать символы, мы приобретаем знание о вещах и их свойствах ${ }^{15}$.

Таким образом, используя в качестве отправного пункта в создании «Философии символических форм» язык как систему символов, Кассирер рассматривает проблему языка с разных сторон: философ прослеживает возникновение человеческой речи с психологической, физической, палеоантропологической, исторической и философской точек зрения, особое внимание при этом уделяется понятию символа и знака, способствовавших развитию членораздельной речи и определивших все дальнейшее развитие человеческой культуры.

Далее философ реконструирует эволюцию понятия «язык» от мимической и аналоговой стадии, через стадию символического выражения - к языку понятийного и концептуального мышления вплоть до наиболее абстрактного языка современной науки. Поскольку Кассирер «разбивает» единый универсум человеческой культуры на ряд автономных областей и язык представляет одну из таких областей, то для того, чтобы прояснить место и значение языка среди прочих феноменов человеческой культуры, философ постоянно соотносит язык с мифом, религией, искусством и наукой (в наибольшей степени эта тенденция прослеживается в «Опыте о человеке»).

Философия языка Кассирера является, следовательно, важнейшим элементом его философии культуры и философской антропологии, определяющим символическую природу человека, формы человеческой коммуникации и пути построения символического универсума культуры.

15 Cassirer E. Philosophie der symbolischen Formen. Bd. 3. Darmstadt, 1997. S. 114-115, 124, 154. 


\section{Символизм}

\section{Список литературы:}

1. Кассирер Э. Опыт о человеке. Введение в философию человеческой культуры // Кассирер Э. Избранное. Опыт о человеке. М., 1998.

2. Кассирер Э. Философия символических форм. Введение и постановка проблемы // Культурология. ХХ век. Антология. М., 1995.

3. Малинкин А.Н. Примечание к «Философии символических форм» // Культурология. XX век. Антология. M., 1995.

4. Пархоменко Р.Н. Политические мифы и понятие свободы у Э. Кассирера // Педагогика и просвещение. 2012. № 3.

5. Пархоменко Р.Н. Философия культуры о человеке и его свободе (Э. Кассирер) // Педагогика и просвещение. 2013. № 4.

6. Фохт Б.А. Понятие символической формы и проблема значения в философии языка Э. Кассирера. Тезисы к докладу // Кассирер Э. Избранное. Опыт о человеке. М., 1998.

7. Braun, H.-J./ Holzhey, H./ Orth, E.W.: Über Ernst Cassirers Philosophie der symbolischen Formen. Frankfurt a. M., 1988.

8. Cassirer E. Das Erkenntnisproblem in der Philosophie und Wissenschaft der Neueren Zeit, Bd. 4, Darmstadt, 1973 (zuerst 1957).

9. Cassirer E. Le language et la construction du monde des objets // Journal de Psychologie. XXX e Annee, 1933.

10. Cassirer E. Philosophie der symbolischen Formen. Bd. 1-3. Darmstadt, 1997.

11. Cassirer E. Zur Logik des Symbolbegriffs // Cassirer E. Wesen und Wirking des Symbolbegriffs. Darmstadt, 1997 (zuerst1938).

12. Espersen O. Progress in Language. L., 1894.

13. Hammer-Purgstall. Wiener Academie, Philosoph.-hystorisch. Klasse. Bde. YI-YII, f 1855.

14. Hertz H. Die Prinzipien der Mechanik. Leipzig, 1894.

15. Krois J.-M. Einleitung // Cassirer E. Symbol, Technik, Sprache. Hamburg, 1995.

16. Major David R. First steps in Mental Growst. N.Y.: Macmillan, 1906.

17. Neumann K. Ernst Cassirer: Das Symbol // Grundprobleme der großen Philosophen. Philosophie der Gegenwar. Bd. II. Göttingen, 1973.

18. Paetzold H. Ernst Cassirer. Zur Einführung. Hamburg, 1993.

19. Parkhomenko R. Cassirers politische Philosophie: Zwischen allgemeiner Kulturtheorie und TotalitarismusDebatte. Karlsruhe, 2007.

\section{References (transliteration):}

1. Kassirer E. Opyt o cheloveke. Vvedenie v filosofiyu chelovecheskoi kul'tury // Kassirer E. Izbrannoe. Opyt o cheloveke. M., 1998.

2. Kassirer E. Filosofiya simvolicheskikh form. Vvedenie i postanovka problemy // Kul'turologiya. XX vek. Antologiya. M., 1995.

3. Malinkin A.N. Primechanie k «Filosofii simvolicheskikh form» // Kul'turologiya. XX vek. Antologiya. M., 1995.

4. Parkhomenko R.N. Politicheskie mify i ponyatie svobody u E. Kassirera // Pedagogika i prosveshchenie. 2012. № 3.

5. Parkhomenko R.N. Filosofiya kul'tury o cheloveke i ego svobode (E. Kassirer) // Pedagogika i prosveshchenie. 2013. № 4.

6. Fokht B.A. Ponyatie simvolicheskoi formy i problema znacheniya v filosofii yazyka E. Kassirera. Tezisy k dokladu // Kassirer E. Izbrannoe. Opyt o cheloveke. M., 1998.

7. Braun, H.-J./ Holzhey, H./ Orth, E.W.: Über Ernst Cassirers Philosophie der symbolischen Formen. Frankfurt a. M., 1988.

8. Cassirer E. Das Erkenntnisproblem in der Philosophie und Wissenschaft der Neueren Zeit, Bd. 4, Darmstadt, 1973 (zuerst 1957).

9. Cassirer E. Le language et la construction du monde des objets // Journal de Psychologie. XXX e Annee, 1933.

10. Cassirer E. Philosophie der symbolischen Formen. Bd. 1-3. Darmstadt, 1997. 


\section{Филология: научные исследования 2(14) • 2014}

11. Cassirer E. Zur Logik des Symbolbegriffs // Cassirer E. Wesen und Wirking des Symbolbegriffs. Darmstadt, 1997 (zuerst1938).

12. Espersen O. Progress in Language. L., 1894.

13. Hammer-Purgstall. Wiener Academie, Philosoph.-hystorisch. Klasse. Bde. YI-YII, f 1855.

14. Hertz H. Die Prinzipien der Mechanik. Leipzig, 1894.

15. Krois J.-M. Einleitung // Cassirer E. Symbol, Technik, Sprache. Hamburg, 1995.

16. Major David R. First steps in Mental Growst. N.Y.: Macmillan, 1906.

17. Neumann K. Ernst Cassirer: Das Symbol // Grundprobleme der großen Philosophen. Philosophie der Gegenwar. Bd. II. Göttingen, 1973.

18. Paetzold H. Ernst Cassirer. Zur Einführung. Hamburg, 1993.

19. Parkhomenko R. Cassirers politische Philosophie: Zwischen allgemeiner Kulturtheorie und TotalitarismusDebatte. Karlsruhe, 2007. 